MINOAN LINEAR A 



\section{MINOAN LINEAR A}

by

David W. Packard

UNIVERSITY OF CALIFORNIA PRESS

Berkeley / Los Angeles / London 1974 
University of California Press Berkeley and Los Angeles, California University of California Press, Ltd. London, England

Copyright (c) 1974 by The Regents of the University of California

ISBN: 0-520-02580-6

Library of Congress Catalog Card Number: 73-85794

Printed in the United States of America 


\section{PREFACE}

This book does not set out to identify the language of Linear A. Those in search of comprehensive "decipherments" have at least four recent attempts from which to choose, according to whether they prefer to have the Minoans speaking Greek, Hittite, Indic, or North-West Semitic. What languages were used in Crete before the arrival of the Mycenaeans is still a matter for conjecture-some of those named above are possible-but I believe we can make progress in the study of Linear $\mathbf{A}$ without basing our argument on a hypothetical identification of the language.

A cogent "etymological" interpretation of the texts would have been decisive, but few believe that this has been achieved. The history of scholarship on Linear B before the decipherment provides guidance as to what sort of research is likely to be productive at the present state of our knowledge. The scholars who contributed most towards Ventris's eventual success were Bennett and Kober. Bennett did fundamental work in establishing the signary, in editing the tablets, in preparing indices, and in developing a system of classification which groups together tablets dealing with similar subjects. None of this involved any premature claim to have deciphered the script. Raison, Pope, and a few others have been making important recent contributions for Linear $A$ in the first three areas. In Chapter Two of the present work I have tried to develop a preliminary classification of the Hagia Triada archives. In view of the paucity of material, I have no illusions of approaching the admirable elegance and exactness of Bennett's classification of Linear B; but recognizable divisions exist, and the attempt to find them has been unjustly neglected. I hope at least to have demonstrated that there is enough material to allow some simple conclusions. Intensive contextual study of the Linear B tablets made it possible before the decipherment to predict with considerable accuracy which sign-groups represented personal names, occupational terms, and so forth. This provided a valuable discipline on future etymological speculation. A decipherer who presents a list of Egyptian and Semitic "personal names" 
in Linear A ought to have an explicit theory of how to recognize a personal name on a Minoan tablet. This important preliminary step has too often been ignored.

In addition to helping with the classification of the Knossos tablets, Kober was able to show how inflection could be used as evidence for the Linear B phonetic values. In her 1948 article she correctly deduced the phonetic relationships between about a dozen signs. The problems of Linear A today are not identical with those of Linear B twenty five years ago, and the range of available evidence is different; but we can still profit from Kober's example by resisting the temptation to resort too soon to the "etymological method." In Chapters Three through Five, I have addressed myself to the question of non-etymological evidence for the Linear A phonetic values.

Eight appendices provide various compilations which, I hope, will prove useful to scholars holding diverse views about Linear A. Each appendix is preceded by a brief explanatory introduction.

My initial idea for a statistical study of the Linear A phonetic values originated in 1966 in a Harvard University seminar on computational linguistics taught by Susumu Kuno who generously provided computer time for much of my preliminary analysis. Without his early assistance and encouragement my work on Linear A could hardly have begun. With the addition of a section on the classification of tablets, the study was subsequently expanded into a doctoral dissertation under the guidance of G.P. Goold, himself one of the first scholars to attack Linear A after the decipherment of Linear B. I presented a preliminary report at the Mycenological Congress in Rome in 1967 but postponed further work on Linear $A$ in the hope that the Zakro tablets, discovered five years earlier, would soon be published.

During 1972, I repeated much of the analysis using an improved text and brought the work up to date in other ways. Further delay would undoubtedly have made additional improvements possible. Raison and Pope have announced their new Corpus du Linéaire $A$, and we may hope that the Zakro tablets will eventually be published. Moreover, the final editions of the Knossos and Pylos tablets are scheduled to appear within five years; and Chadwick, in the meantime, is preparing a second edition of Documents in Mycenaean Greek which will include an up-to-date index of sign-groups. His index would have served my purposes better than Morpurgo's excellent but somewhat dated Mycenaeae Graecitatis Lexicon, but I have at least been able to collate her Lexicon with the newest edition of The Knossos Tablets.

I was not able to examine the original Linear A documents in Crete but have consulted photographs and the careful drawings by Pugliese Carratelli. In my earlier work I relied heavily on Brice's transcriptions. The knowledge 
that Pope and Raison had already been at work for several years on a new edition based on repeated autopsy of the documents in the Heraklion Museum dissuaded me from any thought of producing a completely new edition. Their recently published Index implies great divergence from earlier editors. The publication of their Corpus will resolve many doubts, but for the present we must reconstruct their text from their Index. I have discovered more than two hundred places where they differ from Brice. On the assumption that the Index contains essentially the same readings which will appear in the Corpus, I have adopted the Index as my basic standard text. I have not, however, ignored Brice's readings either in my text or in the appendices where they are marked with a special symbol. Pope and Raison very generously made available to me a preliminary copy of their Corpus; but since I consulted this only at a very late stage in my work, it should be assumed that the Index constitutes my basic text.

It will be obvious that computer methods have a major role in this research. I hardly need to emphasize that my conclusions do not possess any special validity simply because a computer was involved. Clerical tasks such as counting and collating can be carried out rapidly by a computer, which makes it feasible to formulate and test a wider range of hypotheses; but the underlying arguments can be understood, and should be presented, with no reference to the machine. To avoid possible misunderstanding on this point, I have deliberately excluded any mention of the computer from my text. Recognizing, however, that some readers may approach this book with more interest in computer techniques than knowledge of Minoan epigraphy, I have included in Chapter One a general survey of Aegean writing.

The book itself, both text and appendices, was set in type by the author using computer photocomposition. Camera-ready copy was prepared on an RCA Videocomp at The Los Angeles Times. This method of typesetting scholarly books, especially those requiring unusual alphabets or difficult page formats, has important advantages in cost, flexibility and speed and deserves to become more widely known. The development of my program for photocomposition was partially supported by an earlier grant from the American Philological Association. I have described this program in an article to appear in the journal Scholarly Publishing.

The programs for the analysis of the Minoan and Mycenaean material were written first in 1967 for an IBM 7094 computer at Harvard. They were subsequently rewritten in 1971-1972 for an IBM 360/91 computer at the University of California, Los Angeles. I wish to thank both universities for their support of my computational work.

I also wish to thank Professor G. Buccellati who advised me on several Akkadian problems, Dr. C. Saporetti whose help has been of great value, and Dr. Paola Negri who kindly provided me with a copy of her un- 
published University of Rome dissertation. Several persons have read the manuscript in varying stages of completion: David Wilson, Professors E.C.H. Carterette and J. Puhvel, and above all Professors G.P. Goold and M. Pope. I am grateful to all of them for their extremely helpful comments, but none should be held responsible for any of my follies.

David W. Packard

University of California

Los Angeles 